\title{
PECULARITIES OF PHOSPHORUS FORMS DYNAMICS IN BOTTOM SEDIMENTS OF RIVER DNIESTER (MOLDOVA)"
}

\author{
Vasile Rusu, Larisa Postolachi, Alexei Maftuleac, Tudor Lupascu \\ Institute of Chemistry of Academy of Sciences of Moldova, 3 Academiei str., MD-2028 \\ tel.: /373-22/ 739731; fax: /373-22/ 739954 \\ e-mail: larisapostolachi@gmail.com
}

\begin{abstract}
Seasonal, spatial and multi-annual dynamics of phosphorus forms in bottom sediments and their interstitial water for river Dniester was evaluated. The spatial dynamics of phosphorus forms in the bottom sediments along river had, in general, the same trend during of 2004 and 2009 years, being recorded the increasing tendency along river Dniester for inorganic phosphorus and decreasing tendency for organic phosphorus. Multi-annual dynamics for 2004-2010 years showed a tendency of increasing of all phosphorus forms in bottom sediments; the highest values being registered during 2010 year. Spatial and seasonal dynamics of phosphorus forms in bottom sediments and their interstitial water were generally in correspondence, although sometimes with some differences.
\end{abstract}

Keywords: bottom sediments, interstitial water, and phosphorus forms.

\section{Introduction}

Phosphorus concentrations in rivers result from both external inputs and internal loading from the bottom sediments [1]. Its chemistry in sediments is greatly influenced by the oxidation-reduction status (redox potential) [2]. Under oxidized conditions, ferric and manganese oxides and hydroxides are important adsorption sites for phosphorus; however, under reducing conditions these minerals are unstable. Mobilization-immobilization processes on the particle surface of sediments occur through interstitial water and its participation [3]. During the desorption process from sediments, phosphorus compounds are accumulated in interstitial water, then according to environmental factors $(\mathrm{pH}$, oxidation-reduction potential Eh, ionic strength, or water mineralization etc.) can be immobilized in the water horizon overlying the bottom sediments. Reverse process, the immobilization from water in sediments, also occurs through interstitial water. Concentrations of phosphorus compounds in the water horizon overlying the bottom sediments and in interstitial water of bottom sediments can vary greatly, and the direction of mobilization-immobilization processes determines pollution - self-purification processes of water bodies.

The objectives of this paper were (i) to evaluate peculiarities of spatial and seasonal dynamics of phosphorus forms in bottom sediments from the Dniester River during 2004, 2009 and 2010, (ii) to perform comparative analysis of phosphorus forms contents in interstitial water and bottom sediments, and (iii) to establish the desorbed amount of phosphorus forms during re-suspension of bottom sediments performed in field and lab conditions.

\section{Case study}

Samples of bottom sediments were collected during the spring and summer of 2004, 2009 and 2010 years along river Dniester (sites Oxentia, Malovata, Vadul lui Voda, Fig. 1).

According to World Health Organization (WHO), phosphorus compounds occurred in natural waters are classified into 12 phosphorus forms (Fig. 2), by chemical type - (i) orthophosphates, (ii) acid hydrolysable phosphates (poly- and pyrophosphates), (iii) organic phosphorus, (iv) total content, and by physical state - (i) dissolved (filterable), (ii) particulate, (iii) total content [4]. Additionally, this scheme was tested for estimation of phosphorus content in bottom sediments being determined (i) inorganic phosphorus (orthophosphate plus condensed forms - polyphosphates and pyrophosphates), (ii) organic-phosphorus and (iii) the total amount of phosphorus [5].

In order to determine content of inorganic and organic phosphorus compounds in the bottom sediments, fresh (wet) samples were used. Scheme for determination of phosphorus forms in bottom sediments presents a summary of existing methods being determined (i) inorganic phosphorus (orthophosphate plus condensed forms), (ii) organic phosphorus and (iii) the total amount of phosphorus in sediments. The amount of total phosphorus was determined according to U.S. Geological Agency [6]. The content of inorganic phosphorus was determined according to WHO methods for inorganic particulate phosphorus [4]. The amount of organic phosphorus was obtained by subtracting inorganic phosphorus from the amount of total phosphorus.

Content of phosphorus forms in interstitial water was determined after centrifugation of fresh (wet) sediments. There were established amount of orthophosphates, condensed and organic phosphorus according to World Health Organization recommendations [4].

Re-suspension was performed in natural conditions by „aquarium” method [7]. To perform desorption from sediments in lab condition, fresh (wet) samples were stirred in a portion of distilled water for 2 hours.

\footnotetext{
『 This article is an extended abstract of a communication presented at the Conference Ecological Chemistry 2012
} 


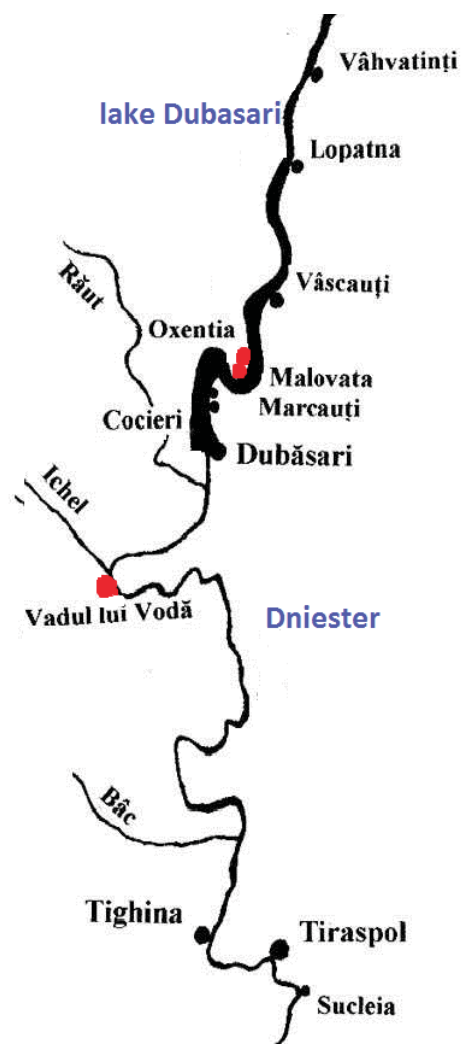

Fig. 1. Hydrographical basin of Dniester River. Sampling sites - Oxentia, Malovata, Vadul lui Voda

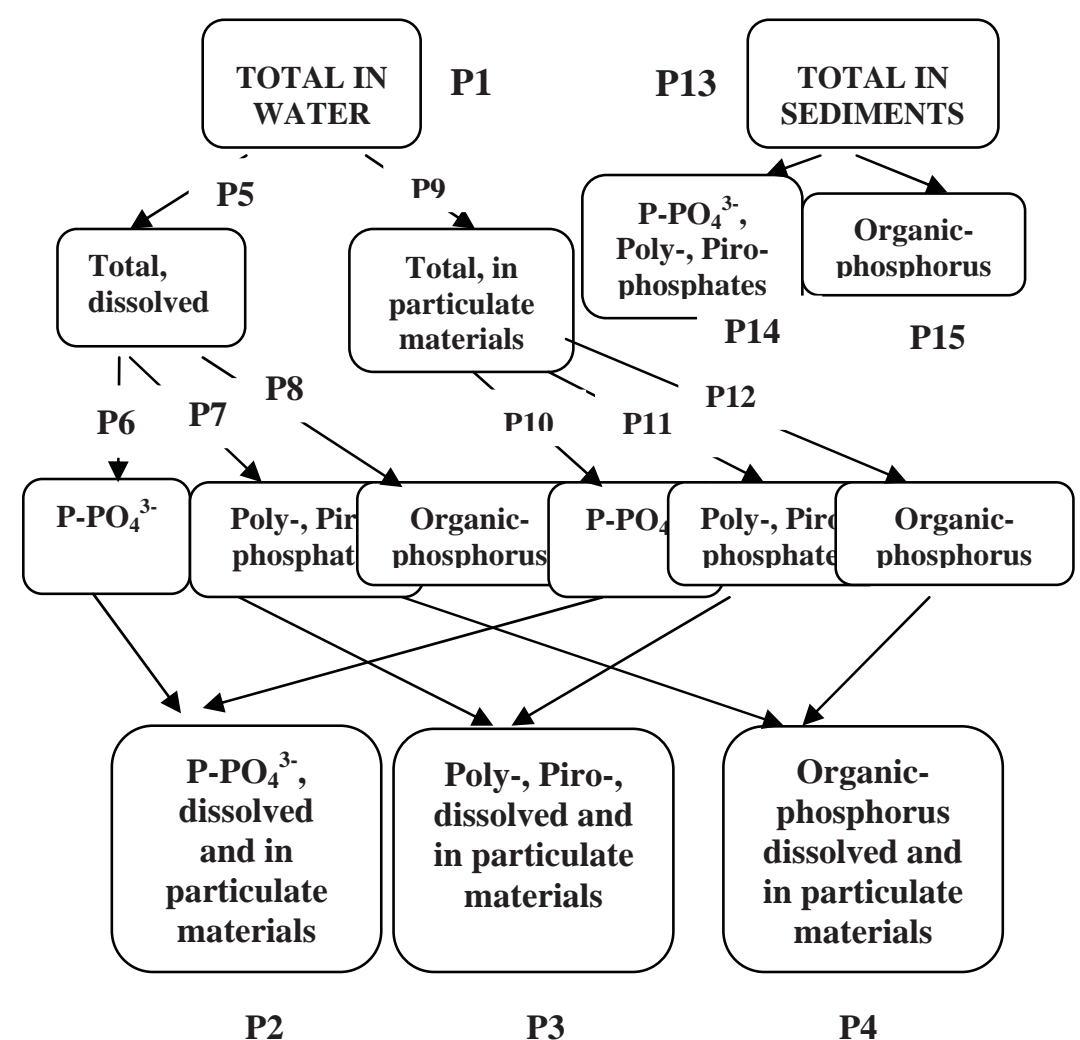

Fig. 2. Phosphorus forms in natural waters for the entirely system "water-particulate materials-bottom sediments". Scheme for analysis of the phosphorus forms in water and particulate materials according to World Health Organization classification (forms P1-P12, [4]). Supplemented scheme for analysis of the phosphorus forms in sediments (forms P13-P15, [5]) 


\section{Results and discussion}

The spatial dynamics of phosphorus forms in the bottom sediments during summer of 2004 and 2009 years had, in general, the same trend (Fig. 3). Thus, the content of inorganic phosphorus (Pinorg) had been increased in bottom sediments along Dniester River. The content of organic phosphorus (Porg) had been decreased along the river, the highest values of their content being recorded in bottom sediments of Dubasari Lake (sites Oxentia and Malovata).

Dynamics of the content of phosphorus forms in the bottom sediments was different during the years. Multiannual dynamics of inorganic (Pinorg) and organic (Porg) phosphorus forms in the bottom sediments is presented in figure 4. Thus, for Vadul lui Voda location (site) the tendency of increasing of all phosphorus forms in bottom sediments was characteristic. The ratio of Pinorg : Porg forms in bottom sediments was not homogeneous during these years (Fig. 5), although more frequently the percentage of inorganic phosphorus (Pinorg) prevailed over organic (Porg) phosphorus.
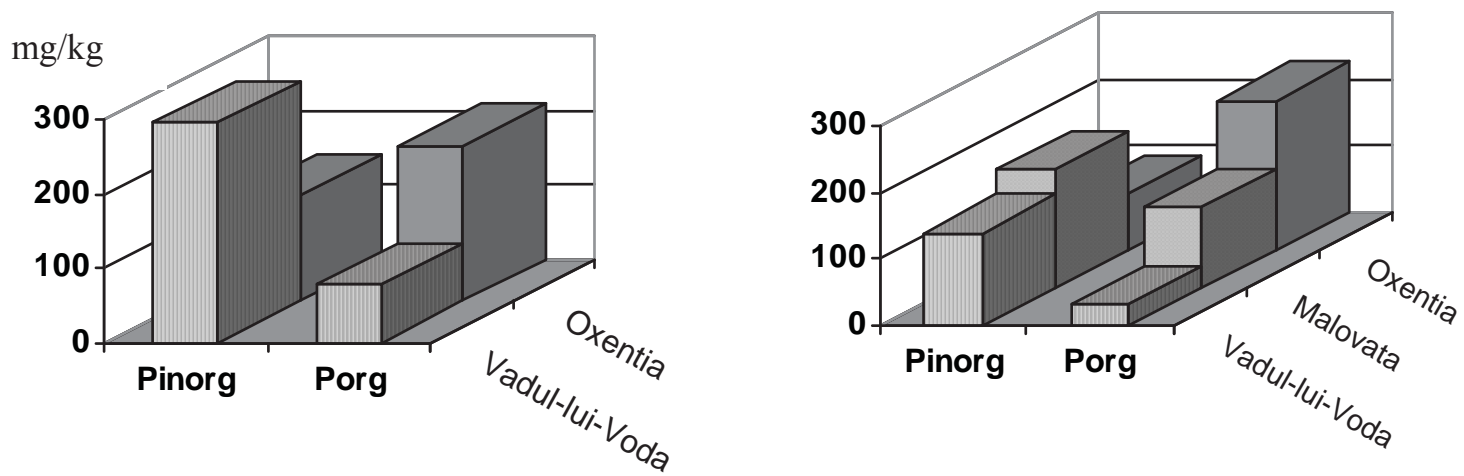

Fig. 3. Spatial dynamics of inorganic ( $\mathrm{P}$ inorg) and organic ( $\mathrm{P}$ org) phosphorus forms in the bottom sediments along river Dniester during of 2004 and 2009 years (summer)

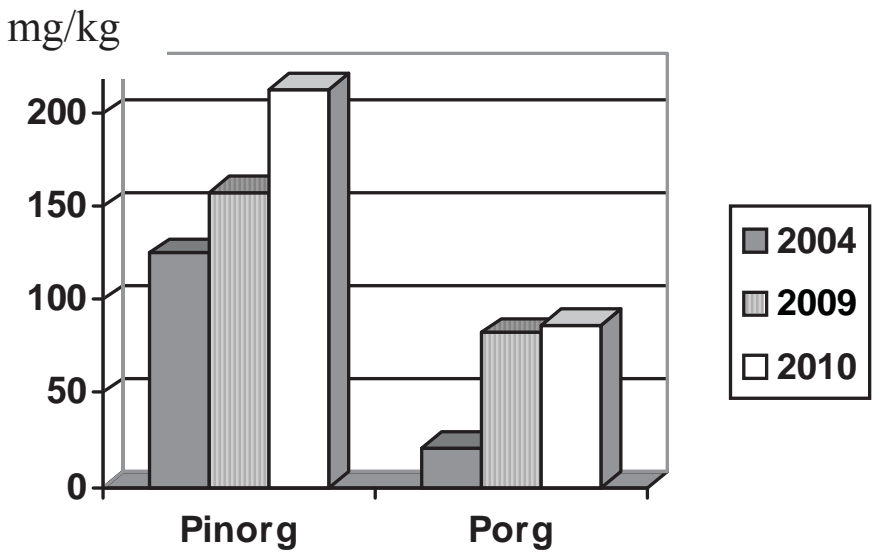

Fig. 4. Multi-annual dynamics of inorganic ( $\mathrm{P}$ inorg) and organic ( $\mathrm{P}$ org) phosphorus forms in the bottom sediments during of 2004, 2009 and 2010 years (site Vadul lui Voda, spring)

The seasonal dynamics was also less distinct. The content of inorganic phosphorus for sediments sampled in lake Dubasari (site Oxentia) decreased and organic phosphorus increased from spring to summer during researched years (Fig. 5). For bottom sediments from Vadul lui Voda site the dynamics of these forms was rather somewhat inverted.

Spatial dynamics of phosphorus forms in interstitial water was different as compared for bottom sediments. During summer of 2009 year the content of inorganic phosphorus decreased, while the content of organic phosphorus increased in interstitial water along Dniester (Fig. 6). For Vadul-lui-Voda site, seasonal dynamics of phosphorus forms in bottom sediments and their interstitial water was generally in correspondence (Fig. 7). As whole, the tendency of increasing of inorganic phosphorus in interstitial water was registered from the spring to summer (Fig. 8). 

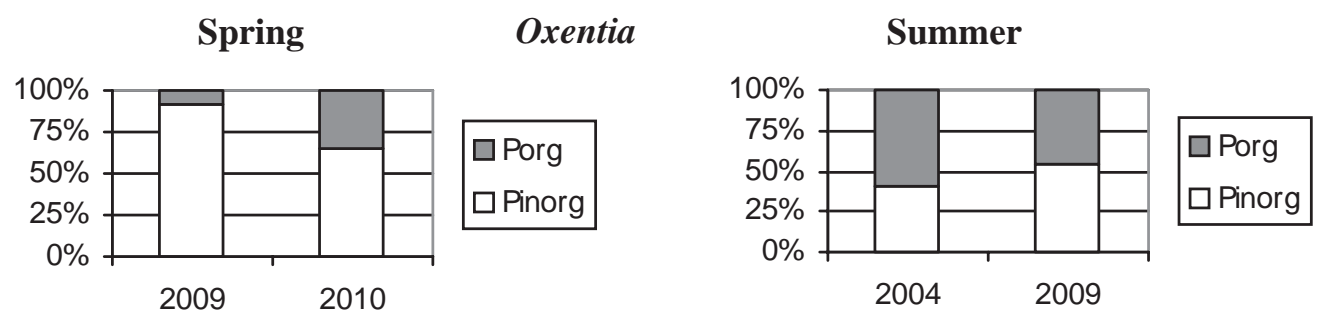

Vadul-lui-Voda
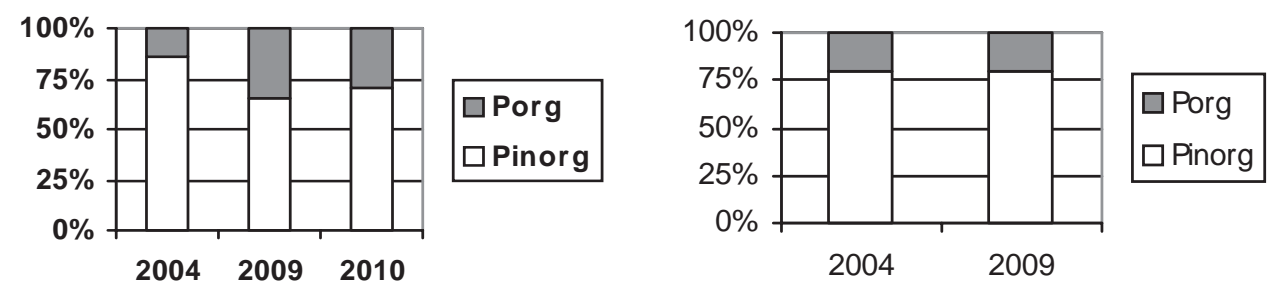

Fig. 5. Proportions of inorganic (P inorg) and organic (P org) phosphorus in bottom sediments along river Dniester during spring and summer of 2004, 2009 and 2010 years

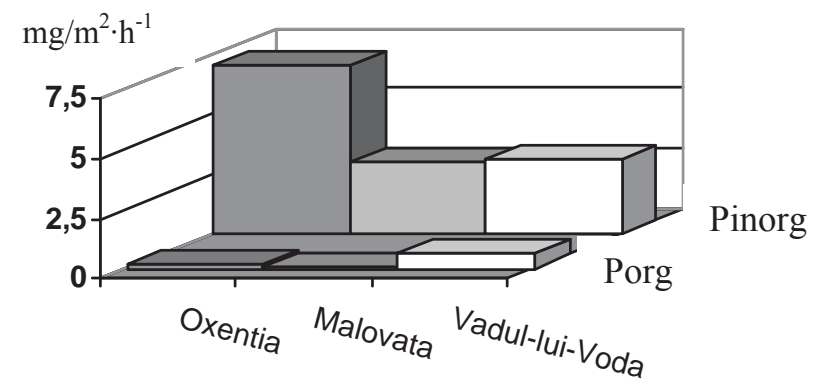

Fig. 6. Spatial dynamics of phosphorus forms (inorganic and organic) in interstitial water of sediments during of summer of 2009 year. Data computed per layer of sediments with $5 \mathrm{~cm}$ of thickness (h) and an area (S) of $1 \mathrm{~m}^{2}$

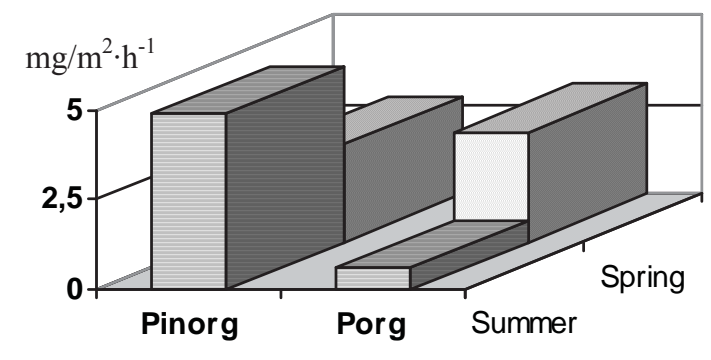

Fig. 7. Seasonal dynamics of phosphorus forms (inorganic and organic) in interstitial water of sediments during of 2009 year (Vadul-lui-Voda site). Data computed per layer of sediments with $5 \mathrm{~cm}$ of thickness (h) and an area (S) of $1 \mathrm{~m}^{2}$.

\section{Oxentia}

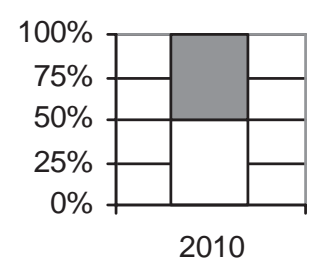

\section{Spring}

Vadul-lui-Voda
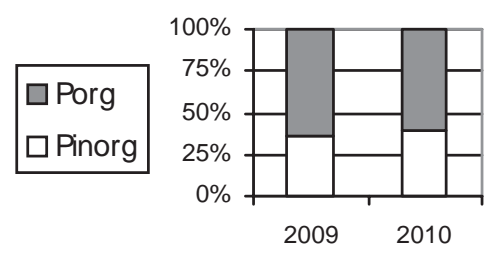

\section{Summer}

Oxentia

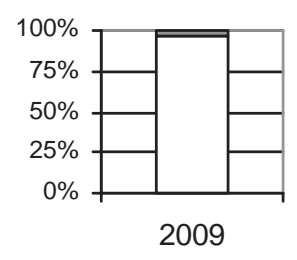

Vadul-lui-Voda

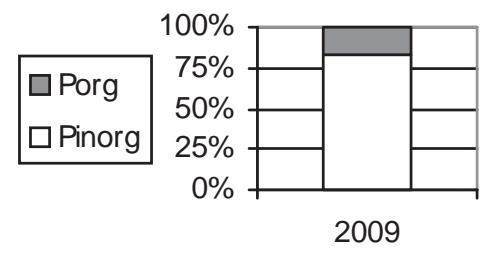

Fig. 8. Proportions of inorganic (P inorg) and organic ( $\mathrm{P}$ org) phosphorus in interstitial water of bottom sediments along river Dniester during of spring and summer of 2009 and 2010 years

During the turbulent moments (e.g. winds), the bottom sediments are re-suspended in water horizon above sediments, i.e. the re-suspension phenomena (RES) takes place. In such conditions the content of phosphorus orthophosphate in water layer (W) above sediments can increase for about 3,1 times, compared with its content in quiet conditions (Fig. 9). The content of poly- and pyrophosphates may increase for about 1,4 times, which constitutes about $43 \%$ from its content in interstitial water (IW). 


\section{Orthophosphates}

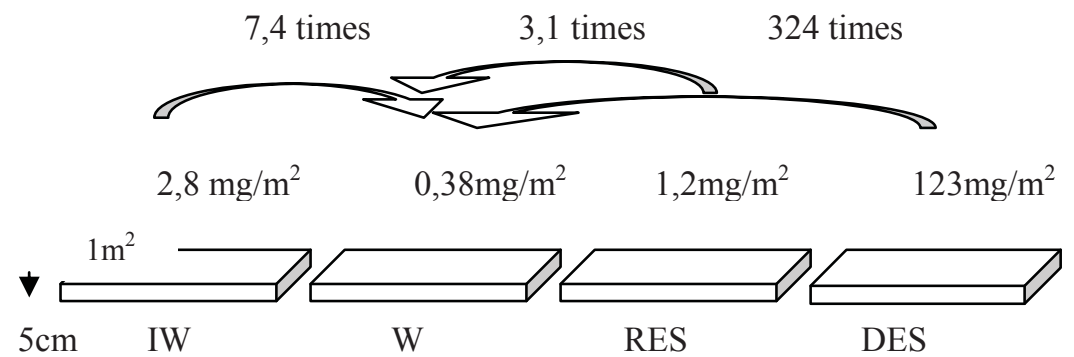

Poly-, pyrophosphates

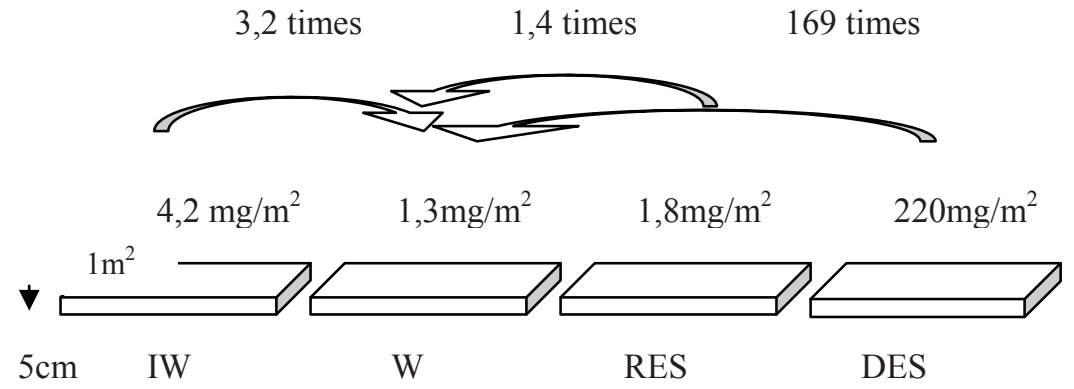

Fig. 9. Phosphorus forms dynamics in water (W) and interstitial water (IW) of sediments along Dniester River during of summer of 2009 year (site Oxentia). Phosphorus mobilization during the re-suspension of sediments in field conditions (RES) and desorbed amounts (DES) from sediments in lab conditions. Data computed per layer of sediments with $5 \mathrm{~cm}$ of thickness $(\mathrm{h})$ and an area $(\mathrm{S})$ of $1 \mathrm{~m}^{2}$

Lab modeling of re-suspension of bottom sediments shows that considerable amount of phosphorus is desorbed from bottom sediments (Tab.). Results presented in the table demonstrate that under such conditions about 1,5-29\% from total quantity of inorganic phosphorus and $0,2-27 \%$ from total quantity of organic phosphorus can be desorbed from sediments.

Phosphorus amount desorbed from bottom sediments of the Dniester River (lab modeling).

\begin{tabular}{|c|c|c|}
\hline Site & P inorganic desorbed, $\%$ & P organic desorbed, $\%$ \\
\hline \multicolumn{3}{|c|}{ Spring } \\
\hline \multicolumn{3}{|l|}{2004} \\
\hline Vadul lui Voda & 29 & - \\
\hline \multicolumn{3}{|l|}{2009} \\
\hline Oxentia & 1,5 & 19 \\
\hline Vadul lui Voda & 3,4 & 3,8 \\
\hline \multicolumn{3}{|c|}{ Summer } \\
\hline \multicolumn{3}{|l|}{2004} \\
\hline Oxentia & 22 & 0,5 \\
\hline Vadul lui Voda & 16 & 27 \\
\hline \multicolumn{3}{|l|}{2009} \\
\hline Oxentia & 8 & 0,2 \\
\hline Malovata & 6,6 & 0,3 \\
\hline Vadul lui Voda & 3,6 & 0,6 \\
\hline
\end{tabular}

\section{Conclusions}

The spatial dynamics of phosphorus forms in the bottom sediments had, in general, the same trend during summer of 2004 and 2009 years, being recorded along river the increasing tendency for inorganic phosphorus and decreasing 
tendency for organic phosphorus. Multi-annual dynamics for 2004-2010 years showed a tendency of increasing of all phosphorus forms in bottom sediments, the highest values being registered during 2010 year. Spatial and seasonal dynamics of phosphorus forms in bottom sediments and their interstitial water were generally in correspondence, although sometimes with some differences. The results suggest that during of re-suspension the bottom sediments can become a relevant source of phosphorus, being mobilized significant amounts of phosphorus in water horizons above the sediments.

\section{References}

[1]. Ruban, V.; Lopez-Sanchez, J.; Pardo, P. et al. J. Environ. Monit. 1999, 1; 51-56.

[2]. Pierzynski, G. M., Ed. Methods of Phosphorus Analysis for Soils, Sediments, Residuals, and Waters. SAAESD: Kansas, 2000.

[3]. Rusu, V.; Lupascu, T. Chemistry of aquatic sediments. Surface properties. Physico-chemical models. Chisinau, 2004. -272 p. (Rom).

[4]. Madera, V.; Allen, H. E.; Minear, R. A., Eds. Examination of Water for Pollution Control, World Health Organization. Pergamon Press: Copenhagen, Denmark, 1982; 1st Ed., vol. 2; pp. 310-319.

[5]. Rusu, V.; Postolachi L. In Air and Water components of environment, 2011; 206-213.

[6]. Fishman, M.; Friedman, L. Eds. Techniques of water-resources investigations of the United States Geological Survey. Washington, 1989, Book 5, 3d edition; pp. 367-373.

[7]. Martinova, M. Nitrogen and phosphorus in bottom sediments of lakes. Moscow, 1984. -160 p. (Russ). 